\title{
O espaço da leitura em Bizâncio
}

\author{
Lyvia Vasconcelos Baptista
}

CAVALLO, Guglielmo. Lire à Byzance. Traduit par Paolo Odorico et Alain Segonds. Paris: Les Belles Lettres, 2006, ISBN: 978-2-25144309-6, 165 p.

Importante obra desenvolvida a partir da experiência de Guglielmo Cavallo em pesquisas e seminários ligados ao Centre d'Etudes Byzantines Neo-Helléniques et Sudest Européennes da École des Hautes Etudes en Sciences Sociales (EHESS - Paris), traduzida para o francês por Paolo Odorico e Alain Segonds, Lire à Byzance foi publicada com o objetivo de oferecer aos pesquisadores e alunos um material inédito e de qualidade sobre a história da leitura na civilização bizantina.

A questão que permeia todo o esforço da obra pode ser assim formulada: quais são os traços que podemos perceber das leituras laicas, eclesiásticas ou monásticas deixados nos livros conservados e acessados por nós, leitores modernos? A resposta comporta, em doze capítulos, uma análise do livro na sociedade bizantina, com suas funções, sentidos e tipologias, bem como as modalidades, maneiras e situações que articulam a relação com o leitor. A leitura é vista, portanto, como algo que pressupõe o envolvimento de espaços sociais, práticas culturais e construção de sentidos.

Dentre as categorias trabalhadas na obra, a ideia de uma "mentalidade livresca", presente em Bizâncio, é, talvez, a principal. Tal mentalidade, explica Cavallo, é proveniente da estrutura de autoridade da escrita e se manifesta de diferentes formas: pela mania de colecionar livros, pelo valor da Bíblia, pelo repertório fixo de conhecimentos, entre outras.

O conjunto da obra permite a visualização da formação de seu autor: eminente especialista em paleografia grega e civilização bizantina. Cavallo procura estabelecer sempre uma clara aproximação entre esses campos, percebendo a influência das formas greco-romanas no cotidiano bizantino (já que os próprios bizantinos, justifica Cavallo, consideravam-se como "romanos"), uma vez que pertence à categoria de pensadores que não veem rupturas radicais entre as artificialmente construídas unidades-tempo da História.

Inicialmente, vemos apresentadas as possibilidades de se fazer uma história da leitura em Bizâncio, dificultadas pela ausência de traços diretos e pela complexidade interpretativa dos traços indiretos em relação a esse fenômeno. Cavallo expõe as fontes utilizadas: produção documental, documentos iconográficos, fontes literárias, catálogos ou inventários de bibliotecas e os livros que chegaram até à contemporaneidade (apresentando traços concretos da leitura); as dificuldades metodológicas (como delimitar a atividade da leitura? Que tipo de leitura considerar?) e evidencia a importância de se pensar, primeiramente, a relação entre livros de conteúdo teológico e livros de conteúdo profano. Ora, apesar da existência de um forte cânone retórico pautado nas obras clássicas, a produção literária só poderá, nesse momento, residir massivamente no âmbito do sagrado. Em todo nível de instrução, do mais modesto ao mais elevado, são os livros de conteúdo teológico os mais lidos.

A compreensão do tema se torna ainda mais complexa quando se percebe que, entre os bizantinos, o livro não é apenas instrumento de leitura, mas também um possível texto-autoridade, comportando significados mais profundos. O que estava escrito adquiria valor absoluto e exigia, portanto, certa submissão, e mesmo os analfabetos o sabiam. O reverso disso, argumenta Cavallo (p. 146), é a destruição do livro, que acompanha formas de repressão intelectual. Ao queimar um livro, o ato que se representa é a destruição daquilo que está escrito, do conteúdo, por assim dizer.

Guglielmo Cavallo explica que na antiguidade a leitura era definida (por volta do I e II séculos d.C.) como "enunciação de um texto escrito em voz alta e forte" (p. 14-15). Tratava-se de uma forma de interpretação ou de performance, oral e visual, como também encontraremos no Império Bizantino. Quanto aos métodos, na antiguidade a leitura será 
ou muito extensiva (ler numerosas obras, tentando obter o sentido essencial dos textos) ou muito intensiva (ler atentamente, parando e revendo o que já foi lido). No período bizantino a leitura intensiva ganha novos contornos e configura-se como a técnica predominante. Já em relação à constituição das bibliotecas públicas e privadas o autor dirá que, a despeito das diferenças entre essas práticas na antiguidade greco-romana e em Bizâncio, resultado de uma nova morfologia social e cultural, o hábito de colecionar livros sempre permaneceu.

Embora a prática docente não fosse muito promissora, a alfabetização tinha significativo valor, pois poderia levar o indivíduo a assumir importantes cargos civis, militares ou eclesiásticos (ainda que, mesmo os analfabetos pudessem chegar ao poder). A herança romana moldou, em Bizâncio, um Estado profundamente burocrático, caracterizado por uma rede extensa e heterogênea de funcionários, bem como por uma vasta documentação escrita, presentes por todo o império. Além das competências técnicas, era preciso desenvolver nos altos funcionários uma aprendizagem de gramática e retórica, almejando a redação de cartas, tratados ou outras exigências imperiais.

Entre as mulheres, o analfabetismo e o semianalfabetismo eram bastante acentuados. $\mathrm{O}$ modelo de educação feminina, adotado em Bizâncio, foi o de uma instrução mínina, quando não ausente, quase absolutamente religiosa. Por esse motivo as mulheres, ainda que no século XI ocorra uma significativa abertura à prática da instrução feminina, nunca constituíram uma camada de verdadeiras leitoras.

Um bizantino tornava-se verdadeiramente leitor frequentando escolas. Alguns poderiam passar ao nível secundário. Entretanto, pela provável falta de padronização, a instrução secundária apresentava uma diversidade qualitativa e quantitativa de conhecimentos, configurando-se como um ciclo de estudos variado e formador de heterogêneas competências culturais. Já a instrução superior baseava-se, primordialmente, no ensino da retórica que, no seu nível mais alto, objetivava a compreensão não apenas do sentido mais profundo do texto, mas também das preocupações formais do autor.

A leitura não era organizada e transmitida por dispositivos gráficos rigorosos, mas por meio da voz e de suas modulações. As leituras públicas que ocorriam durante as celebrações litúrgicas, em cerimônias solenes, detinham grande importância e se realizavam em auditórios, perante um público selecionado e qualificado ou diante de um círculo de ouvintes bastante amplo. É interessante destacar a prática entre os letrados bizantinos de submeter suas composições ao julgamento de um grupo de eruditos.

A leitura intensiva, realizada com o objetivo de apropriação absoluta do texto, é a prática de leitura mais veiculada em Bizâncio, e estava ligada ao princípio de utilidade, ou seja, àquilo que poderia se tirar do texto lido (benefício moral, intelectual ou de outro gênero). $\mathrm{O}$ autor enfatiza a existência de uma "elite intelectual" que lia intensamente as obras clássicas, embora o referente cristão tenha se constituído como a primordial base cultural entre os bizantinos. A leitura intensiva, enquanto prática erudita, possibilitava o entrelaçamento entre a leitura e a escrita, uma vez que os leitores revisavam, corrigiam erros e inseriam comentários, realizando um esforço de crítica textual ou de interpretação.

Se atestamos a presença e as práticas do leitor "intelectual", seja pelas cópias, citações em fontes, anotaçôes encontradas nas obras, pelos altos cargos que eles ocupavam, seja pelo círculo restrito, pouco homogêneo, todavia reconhecível; o leitor comum, de instrução mediana, não é de fácil localização. Ainda que as duas categorias de leitores aludidas coincidam no caráter utilitário da leitura pouco pautada pelo prazer ou deleite.

Os elementos que envolvem o leitor comum, um tanto vagos pelo imenso campo de oscilação dos níveis de cultura dos atores, são apresentados por Cavallo por meio de casos particulares. De uma forma geral, os livros mais lidos eram os "livros da Igreja”, pela maior adaptação em relação às competências culturais dos leitores. Mas, entre as obras e gêneros veiculados nesse ambiente de leitores medianos, encontramos a historiografia e a crônica.

Intitulado "Escada do Paraíso", em referência à obra de edificação monástica elaborada por João Clímaco (IV d.C.), o autor consagra o maior capítulo à disciplinada leitura monástica, alegando ser o monaquismo um fenômeno extremamente complexo e importante no interior do império bizantino. A elaboração de um livro é apenas mais um dos 
trabalhos para o monge. $\mathrm{Na}$ experiência monástica, o livro é, principalmente, uma mercadoria e seu valor e importância foi aumentando conforme as comunidades monásticas deixavam seus estágios iniciais. A "leitura ascética" tinha como principal propósito a memorização de passagens das Sagradas Escrituras, pela repetição. A maioria dos monges vivia, entretanto, numa situação de substantiva ignorância em relação à leitura e escrita.

Apesar dos livros copiados por monges serem lidos fora dos mosteiros, é preciso considerar a existência das bibliotecas na vida monástica. Formada, principalmente, pelos materiais (escrituras, obras ascéticas e patrísticas, escritos de hagiografia, livros litúrgicos, florilégios, crônicas e raríssimas obras profanas) deixados pelos monges, a biblioteca monástica, no período bizantino, apresentava uma importância diversificada.

O autor dedica o penúltimo capítulo à discussão daquilo que ele chama "littérature des marginalia", resumida às notas escritas pelos autores nas margens dos livros e caracterizada como uma continuação do livro lido. Trata-se da análise de traços deixados pelos leitores bizantinos, nos livros, e permite a compreensão de algumas atitudes ou reaçôes do leitor em ligação direta com o texto.

O último capítulo é dedicado ao objeto-livro, uma vez que a leitura funcional se realizava em diversos materiais, mas é a capacidade de ler um livro que caracteriza aquele leitor com competências culturais significativas. Além disso, o livro porta um valor de fato (material e espiritual), ainda que variável, na sociedade bizantina. O status de "indivíduo culto" era conquistado de acordo com a quantidade de livros por ele manuseada.

É ressaltando as relações entre as formas materiais do livro e o complexo sistema ideológico da sociedade bizantina que o autor encerra sua exposição. Demonstrando uma preocupação constante com a variedade e clareza das fontes textuais utilizadas - Gregório de Nazianzo, IV d.C.; Michel Psellos, XI d.C.; João Crisóstomo, IV d.C.; João Tzétzés, XII d.C.; Gregório de Nissa, IV d.C.; Anna Comnena, XII d.C.; Nicetas Choniates, XII d.C., dentre outras -, Guglielmo Cavallo, ao pretender nos informar sobre o espaço da leitura em Bizâncio, compõe uma obra importante em ou- tros e muitos aspectos: como material praticamente inédito entre os estudos bizantinos, como instrumento de profícuas reflexões acerca do estatuto da leitura na sociedade, como inspiração e conhecimento para o estudo da sociedade e cultura no Império Bizantino e, principalmente, como modelo bem-sucedido de investigação histórica. 